\title{
An integrative approach to rangeland condition and capability assessment
}

\author{
O.J.H. BOSCH AND J. BOOYSEN
}

\begin{abstract}
Authors are respectively professor and senior research scientist, Department of Plant and Soil Sciences, Potchefstroom University for CHE, Potchefstroom, 2520, South Africa.
\end{abstract}

\begin{abstract}
A comprehensive system has been designed to serve as a basis for rangeland condition and grazing capacity assessment. It is important that research information and knowledge be transferred to land managers in the most usable form. An approach has therefore been developed by which different computer technologies are combined to produce a unique and user friendly package for direct application by the grazing industry. The system can be applied universally, regardless of the pool of quantitative knowledge that exists. This is of special importance for the evaluation and monitoring of the many rangeland systems not yet understood and quantified.
\end{abstract}

Key Words: expert system, data base, range condition, degradation gradients, plant production, grazing capacity.

Several techniques have been developed for assessing the condition and capability of rangelands (e.g., Dyksterhuis 1949, Tueller and Blackburn 1974, Haydock \& Shaw 1975, Foran et al. 1978, Christian et al. 1978, Tainton et al. 1980, McKeon et al. 1982, Vorster 1982, Barnes et al. 1984, Foran et al. 1986, Mosley et al. 1986, Uresk 1990). These techniques make use of data such as the ecological status of species and their forage production potential, and production simulation models. However, these data and models (stochastic) are extremely limited and localized. The extrapolation potential of the techniques is, therefore, also limited and a particular technique would in most cases only be of real value in the area where it was developed.

A need therefore existed to develop a comprehensive system that would enable rangeland scientists to compile a data base for all existing relevant data that are required for the assessment of condition and grazing capacity in different homogeneous grazing areas. A requirement was that the system has to be developed in such a way that, once the data base is completed, an assessment of the condition and grazing capacity of any management unit in the area under consideration would be possible.

Implementation of such a comprehensive system will require large amounts of data from different disciplines, the use of various analytical procedures, and the ability to effectively interpret the results. Further needs were therefore to develop computer software that:

- would be able to accommodate the knowledge and expertise on vegetation condition and production related aspects in one convenient and efficient package, and

-that would form a uniform mouthpiece for the various subdisciplines, allowing a dynamic flow of information to the end user, across the usual barriers of information dissemination.

The aim of this paper is therefore to describe an approach by which different computer technologies are integrated and used to produce an effective and user friendly tool for rangeland planners and managers. Although the ultimate success of the system will depend upon accurate and reliable subsystem models, the level of sophistication and accuracy of the models used in the system are not of primary concern in this paper. They are mainly applied for illustrating the approach, and could be modified or replaced with more sophisticated models that might be available for a particular area of interest. However, the models that are used in this system, could serve as a basis for implementing the approach in nonquantified and lesser understood rangelands.

\section{Preliminary Considerations}

Traditionally most analytical procedures used for condition and grazing capacity assessment are those in which mathematical equations/models are used, which require specific input data to produce a specific answer. Input data requirements vary considerably depending on the model and are often difficult to obtain. Interpretation of the answer of a model is dependent on model assumptions and deficiencies embedded in the calculations. A specialist is therefore necessary for meaningful deductions and application of the answer.

The proper administration of the data input requirements of models can be improved by the use of a data base. The proper accommodation of the required data greatly enhance the efficiency of model execution. A data base also allows the user to inventory what is available, and when archiving data, built-in quality control ensures the highest level of data integrity. The data required for specific calculations can be extracted as required by the application. However, the extraction of data is still done on the initiative of the user. In view of the difficulties with interpretation of model results mentioned earlier, this can be a further source of the reduction in use of the application.

Partial solution to these problems can be overcome by the use of expert systems. The knowledge base which serves the expert system, is technically a data base that holds specific information and rules about a certain subject. The expert system is based on empirical knowledge of heuristics, generalizations, assumptions, analogous procedures and judgements on the basis of human decisionmaking criteria (Schildt 1987). Thus the heuristic knowledge and reasoning process of specialists can be embedded in the software application. In the strictest sense this still implies an empirical model with limitations in quantifying the total system. The qualitative information of the knowledge base can not substitute quantitative research results. However, the heuristic powers of the expert system in conjunction with models and data bases can serve as a substitute in the absence of a specialist in assisting the user in interpreting and applying final results.

A system has therefore been developed to accommodate all of the above in an attractive package that will aid the rangeland industry in the most dynamic way possible. 


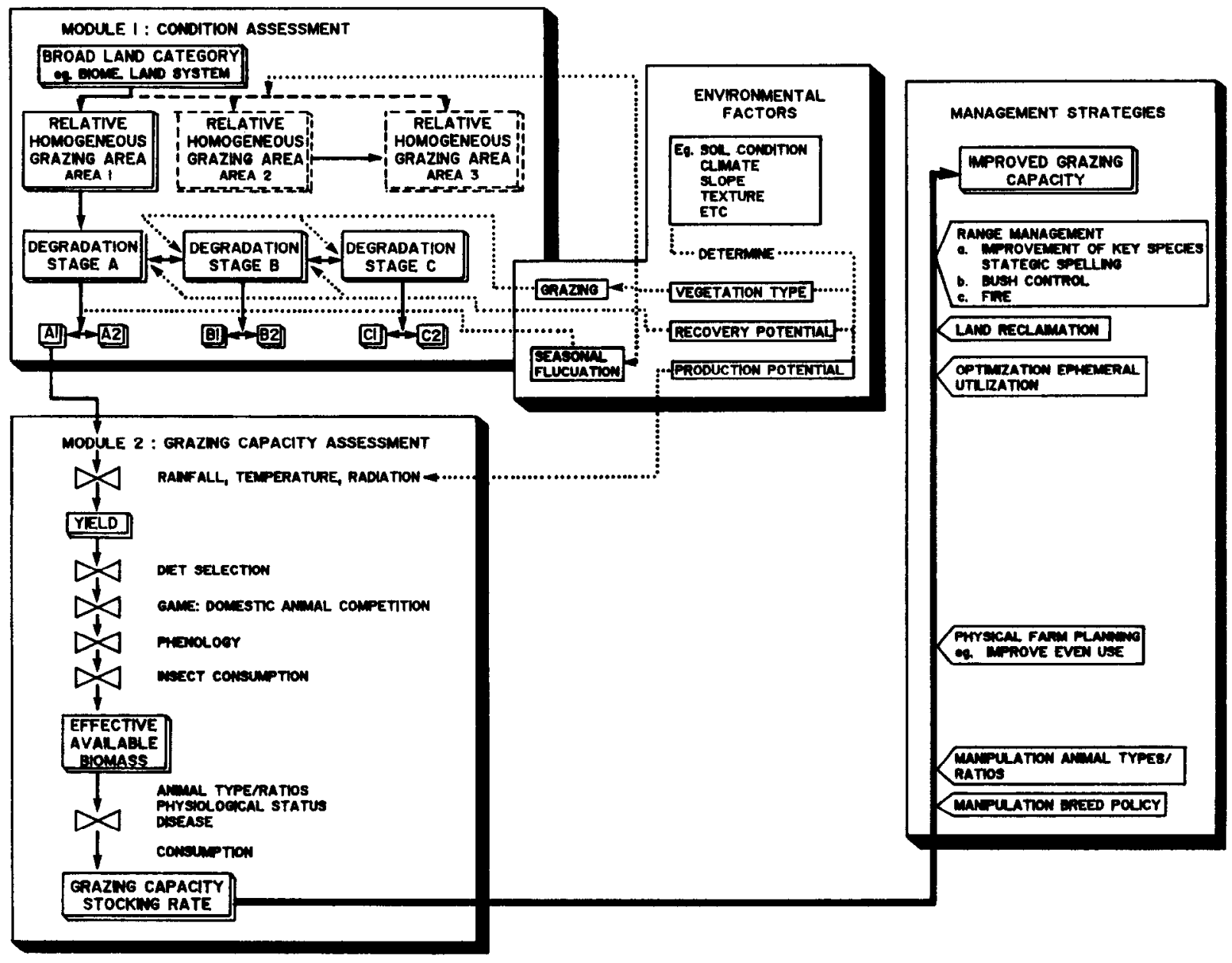

Fig. 1. Schematic presentation of the basic components and types of data required for range condition and grazing capacity assessment and improvement.

\section{System Structure}

When the condition of a particular management unit has to be assessed, it will first be necessary to be able to define the area in which the unit is situated. For this is a sound understanding of the delineation of the broad land categories, into different relatively homogeneous grazing areas will be required. Second, to be able to statistically compare the composition of the management unit with those on the degradation gradient, in order to determine its ecological status, the changes in composition during the processes of degradation will also have to be understood.

A basic framework was therefore constructed which describes the different components and types of data that would be required for a condition and grazing capacity assessment system (Fig. 1). The first module includes a breakdown of the broad land categories into different areas that will be relatively homogeneous with regard to factors such as soil type, topographical position in the landscape, and climate. Within each of these relatively homogeneous areas, different compositions (degradation or seral stagesFig. 1) would further occur as a result of different management practices. Some of these compositional changes would be reversible, while others would not be able to recover to the original composition, due to differences in the recovery potential (e.g., large changes in soil conditions). In more arid areas, large compositional differences also occur due to seasonal variation. Further, the particular sequence and timing of climatic events also leads to multidirectional transitions during the processes of change (Westoby et al. 1989). All these factors could therefore result in a large

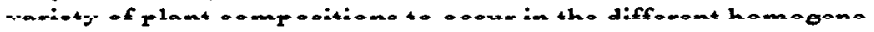

ous grazing areas. Quantification of these compositions and interpretations with regard to their position in the processes of degradation and recovery are prerequisites for the development of an objective condition assessment system.

Each one of the different compositions would be expected to have a different production potential, as determined by its composition and various environmental conditions. The various factors reducing this potential yield to effectively available phytomass, are indicated in the second module of Figure 1. The portions that are not available (e.g., unpalatable material, phytomass loss through natural disappearance or insect consumption, etc.), will have to be taken into account in determining the grazing capacity of a particular management unit.

Interpretation of the condition and grazing capacity assessments allows the user to define possible management options to improve the condition and therefore grazing capacity of the rangeland. For example, if vegetation was degraded to such an extent that its recovery is restricted by unfavorable soil conditions (e.g., eroded surfaces), land reclamation would probably be the only management option to improve the grazing capacity of the particular management unit.

The framework briefly outlined above, was not only used to determine the type of data that will be required, but also to define the structure detail of the total system.

The objectives, technologies, and components of the total system are depicted in Figure 2(a). The integration of the three components, the expert system, simulation models, and knowledge/data base is shown. In the software industrv these comnonents are 
(a)

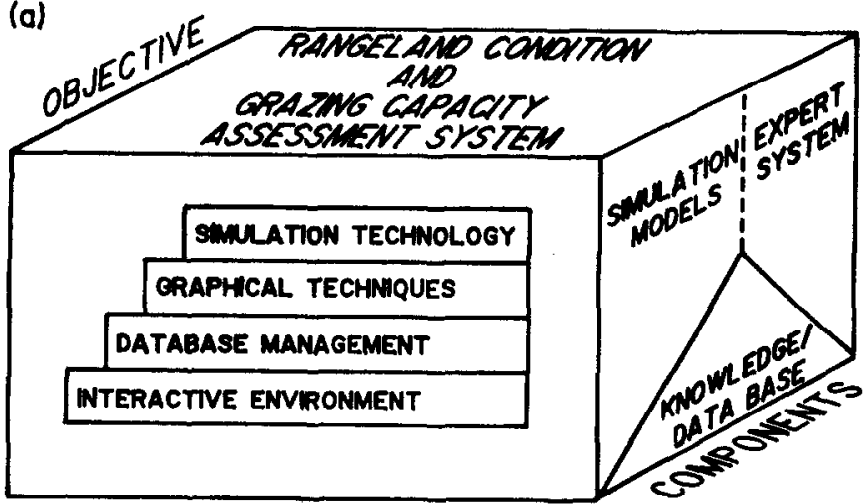

COMPUTEP TECHNOLOGY

(b)

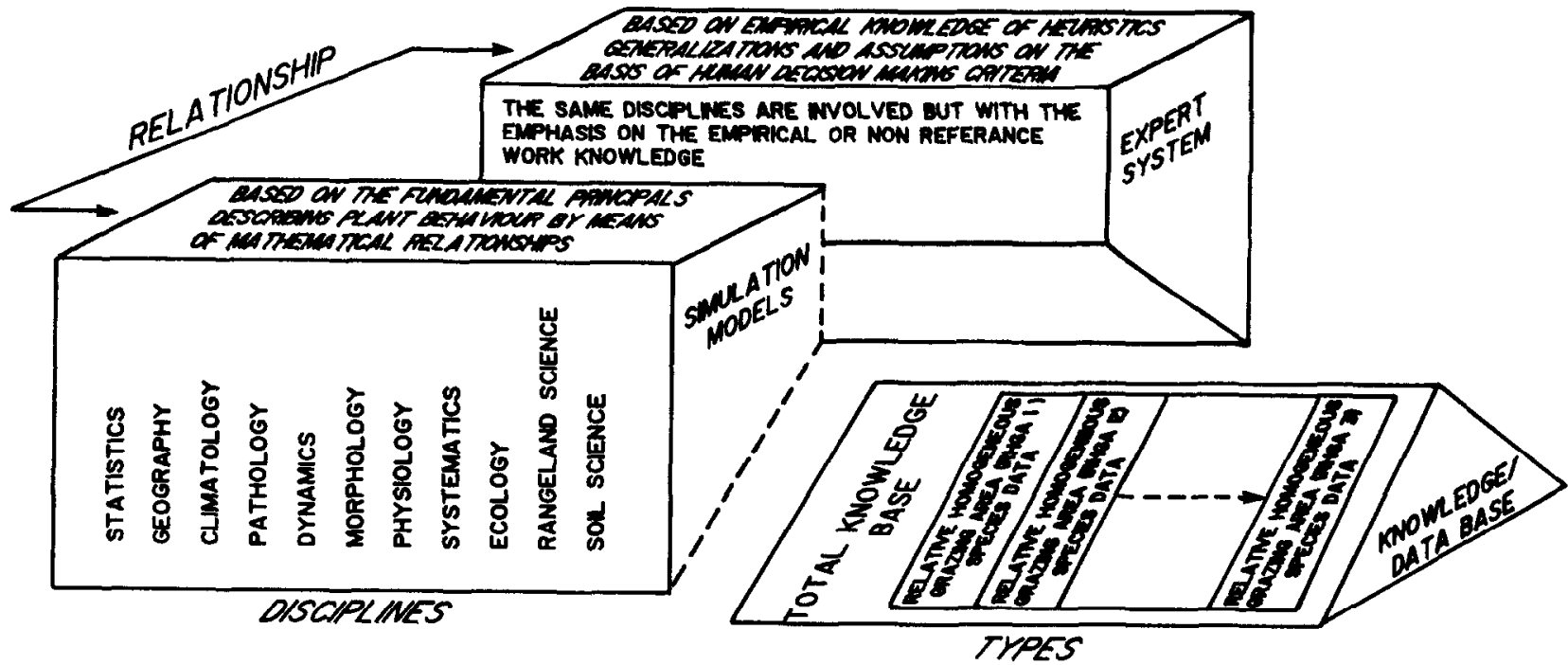

Fig. 2. A schematic presentation of the integration of computer technologies and components for the development of a user friendly system for range condition and grazing capacity assessment.

often distinctly separate units. In this context, however, it should be seen as one complete system in which it is not always possible to define exactly in which component one is operating.

In principle the separation between the model and expert system components is based on the fact that fundamental principles describing species performance by means of mathematical relationships are model components. As previously mentioned, the expert system includes the heuristic knowledge on the basis of human decision-making criteria. A further unique feature of the system is that the data base forms an integral part of the knowledge base. This allows the expert system to act as a supervisor to the novice when interrogating the data base. These main components of the system are outlined in Figure 2(b).

The expert system component is a forward chaining, rule-based system. It initially addresses questions around habitat/location, time of the year, and the phenological state of the vegetation. This sets up the input data requirements from the data base and identifies the appropriate models to be used. Once the range condition is assessed, the expert system guides the user in deriving the potential stocking rate.

Expert systems normally consist of an inference machine and a knowledge base (Schildt 1987). In the present system the inference model was developed by a team of rangeland ecologists, and is fixed because of the application of the system in a specific region. However, the user is allowed to update and/or modify the data bases from within the inference machine. As this is an interactive system, the expert system also allows the user to inspect and/or update the data base at any time during the processing procedures.

The models contained in the model component were constructed from applied research in order to accomplish the objective to assess the range condition and grazing capacity of a management unit or region. These include:

- the weighted average condition assessment model (Bosch et al. 1989a);

- graphical descriptive models of vegetation functional groups on degradation gradients (Bosch 1989, Bosch and Kellner 1991);

- the ecological index production simulation model (Bosch and Booysen 1988);

- a series of accounting models for determining the effectively available phytomass; and

- a model for determining the grazing capacity.

The use of graphical descriptive models is an unique feature being utilized in this system. A calculated answer is not only presented to the user as a value, but it is also put into perspective by means of a graphical representation of a degradation gradient and its associated changes in vegetational and other features. The expert system is again applied in supervising the novice in model inspection and/or modification at any point during processing. It also ensures the highest level of data quality control.

The knowledge/data base is constructed by means of the expert system. For each region identified in the initial part of the inference model, a separate data base is created. The expert system determines the type, number and length of elements building up a record 
in the data base as a function of the number of growing seasons and phenological stages identified. When loading the data base, the expert system's function is to guide the user in an orderly fashion through the data base and provide a graphical indication of the progress. Data pertaining to the data base is specific to the objectives of assessing range condition and grazing capacity. These include:

- The ecological status of a species-A value on a scale from 0 (associated with severely degraded vegetation) to 100 (associated with lightly to under-utilized conditions), obtainable from quantitative gradient studies (Bosch et al. 1989a; Bosch and Kellner, 1991) or expert knowledge (e.g., grazing experiments and literature);

- Production class-Species are classified into 30 production classes (from large tufts, high producers to small tufts, low producers);

- Preference class (palatability) on a scale from 0 (totally unpalatable) to 1 (very palatable) as a function of season and phenological stage;

- Defoliation threshold: Allowable percentage defoliation by which maximum regrowth will be ensured;

- Phytomass loss through insect consumption (expected percentage) as a function of season and phenological stage;

- Disappearance of material through the natural phenological cycle (expected percentage) as a function of season;

- Unavailability of forage due to competition between feral and domesticated animals-Percentage loss to feral animals in the presence and absence of domesticated animals; and

- Animal consumption rates in $\mathrm{kg} /$ day.

\section{Integrative Use of the Data Base, Models, and Expert Sys-} tem: An Illustration

The integrative use of the different computer technologies is illustrated by means of a practical application of the total system in the Mitchell grasslands of western Queensland in Australia.

The minimum field work requirement before using the system, is a survey of the management unit/paddock under consideration. In this example the condition and grazing capacity of a paddock in the Julia Mitchell grasslands (Bosch et al. 1989b) is to be determined. Species composition data were collected during July 1989 in an area representative of the vegetation of the paddock. Nearest plant recordings were made at 200 points, using a step point method (Mentis 1981).

\section{Range Condition Assessment}

On program start-up, the expert system identifies the particular relative homogeneous grazing area in which the paddock is situated, as well as the time of the year in which the survey was

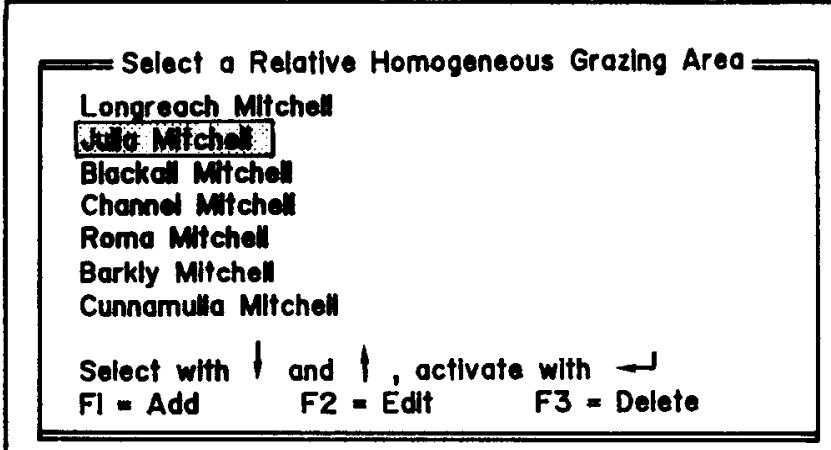

Fig. 3. Self constructed menu (by means of F-keys) for the selection of the relative homogeneous grazing area under consideration.
Select the time of year

Winte]- Cool (le. March to August)

Summer - Worm (le. September to April)

Select with $f$ and $f$, octivate with -

FI $=$ Add $\quad$ F2 $=$ Edf $\quad$ F3 $=$ Delate

Fig. 4. Menu for selection of the time of the year in which the botanical survey was conducted.

conducted. Seven relatively homogeneous grazing areas in the Mitchell grasslands of western Queensland (Fig. 3), and 2 main seasons were identified (Fig. 4). In the case of this example, the user selects the Julia Mitchell homogeneous grazing area, and the cool season. The expert system passes this information onto the data base in order to present the user with all the available species data for the particular area. It also ensures that the appropriate models will be used for all further calculations.

The expert system now supervises the user in selecting the appropriate species from the data base, which were encountered during the field survey. The percentage abundance of each species is entered by the user. At this point the user can inspect the species composition that was entered and edit the data where necessary (Fig. 5).

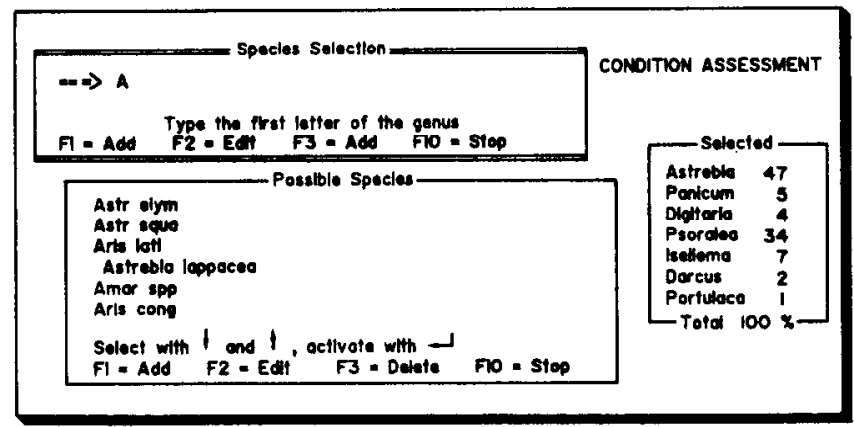

Fig. 5. Frame used for selecting the species encountered in a survey and entering their percentage abundances.

On completion of this step the composition information indicates to the weighted average condition assessment model which information to extract from the data base. In this case the ecological status values of the individual species are extracted and the condition of the vegetation in the particular management unit is determined by calculating the sample vector (position of unit on the appropriate gradient) that was obtained by the weighted average of the species vectors (ecological status values) (Bosch et al. 1989a).

\section{Display of Condition Assessment Result}

After determining the condition of the management unit, the expert system accesses the appropriate graphical descriptive degradation model, and displays the result on this model(Fig. 6). This step facilitates the ecological interpretation of the condition assessment in terms of the ratio between functional species groups (palatable, unpalatable, invader species, etc.), possible trends and recovery potential. The result for the paddock under consideration indicates that the paddock is moderate to moderate severely utilized. Perennial grasses, of which Astrebla lappacea is the dominant species, form the most important functional group of the total composition. Psoralea spp. is associated with overgrazed conditions (Pressland 1984). The relatively high percentage abundance of this species explains the positioning of the paddock slightly 


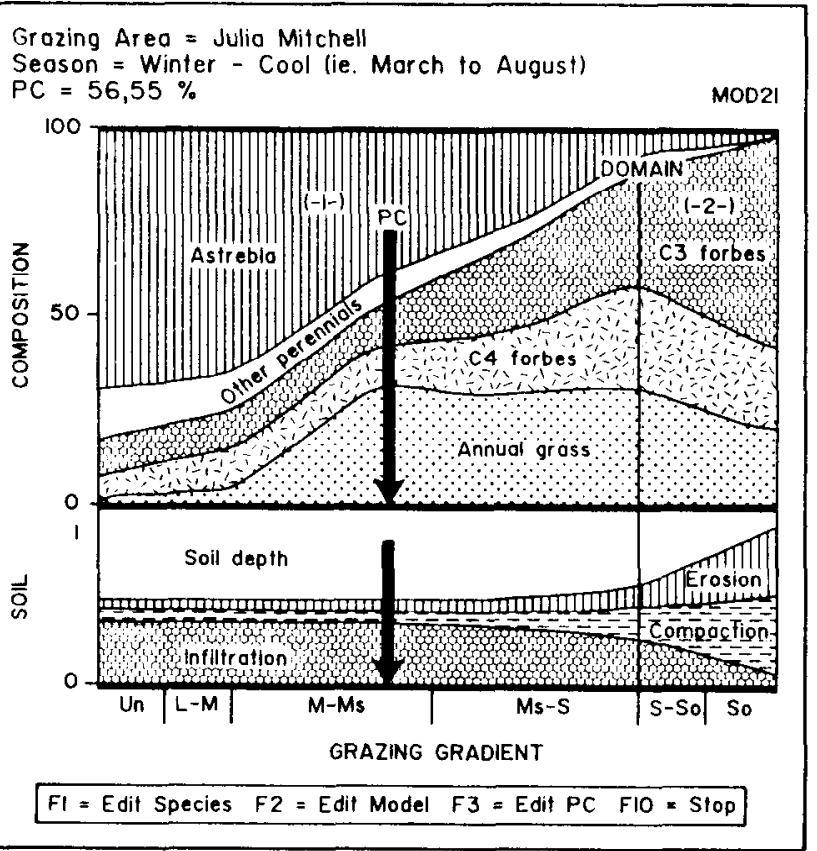

Fig. 6. Display of the condition assessment on the graphical descriptive degradation model for winter compositions in the Julia Mitchell grasslands.

Un-So: Underutilized to severely overutilized

PC: Range condition (position on gradient)

Domains 1 and 2: See text

towards the more degraded section of the gradient. The soils are not eroded or compacted and the vegetation is representative of the first domain of attraction (Bosch and Kellner 1991). Recovery of the vegetation would be possible through normal grazing management procedures, e.g., strategic rest to ensure an increase in the seed production of the perennial species.

At this point various options are available to the user. First, direct access can be obtained to the data base and information in the base can be modified. For example, if new research data are available on the ecological status of the species, the data in the data base can be updated. Second, the composition of the vegetation in the management unit can be changed (e.g., if required, the species that are poor indicators of range condition can be removed to reduce the noise in the data). Third, the graphical descriptive model can also be updated when additional knowledge becomes available. The last option is to continue to the next module for the assessment of the capability of the vegetation in the particular management unit under consideration.

\section{Grazing Capacity Assessment}

The rainfall for the total growth season or specific season of interest for the area under consideration is entered by the user. The production model extracts the relevant input data (production classes of species contributing to composition under consideration) from the data base and together with the amount of rainfall, determines the total phytomass production that could be expected from the vegetation in the particular condition state. In the case of the paddock in the Julia Mitchell grassland, an average seasonal (cool months) rainfall of $153 \mathrm{~mm}$ was entered and the expected total potential yield was calculated as $790 \mathrm{~kg} / \mathrm{ha}$ (Fig. 7).

This value is presented to the user with the options of either to change the model, or to replace the calculated production result to a value obtained from an external resource (e.g., from a more sophisticated model). Dircct access can also be made to the data
Productlon class 1: $89.200 \%$

Production class 2: $7.400 \%$

Production closs 3: $0.400 \%$

Potentlal Yleld : $790 \mathrm{Kg} / \mathrm{ho}$

FI Model F2 Specles F3 External F1O Continue

Input progress

o $100 \%$

Fig. 7. Estimation of expected potential yield.

(F-keys: see text).

base to modify the species data if required.

As mentioned before, not all phytomass produced is effectively available to the grazing animal. Continuing with the determination of the grazing capacity of the particular rangeland under consideration consists of a continuous shuttle between the expert system and data base. In this process the series of accounting models are used for the calculation of the various components of phytomass loss or non-availability until the net phytomass available to the grazing animals is reached (Fig. 8).

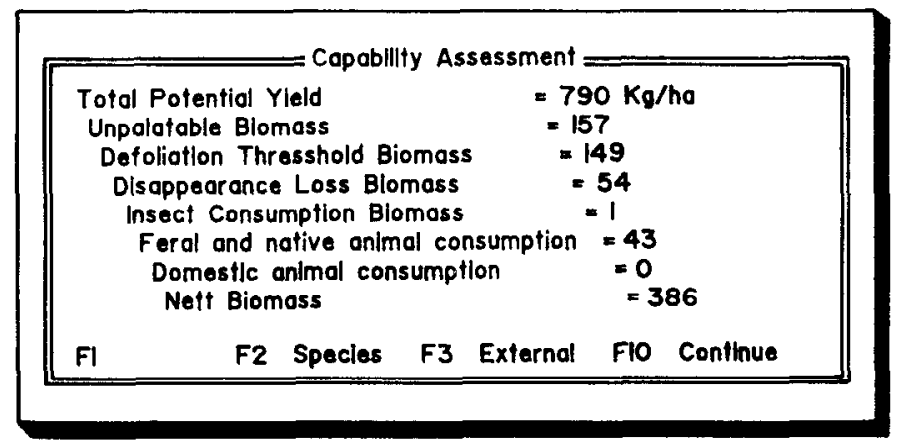

mput progress

0

$100 \times$

Fig. 8. Results of the calculations of phytomass loss or non-availability. (F-keys: see text).

The accounting procedure utilizes the values in the data base, which are based on either expert opinion or hard data. However, it is acknowledged that the nature and interaction of these components are more complex and should be quantified by means of mathematical relationships. An effective model dealing with all these components as defined in this system could not yet be identified. If any particular calculated value proves to be unsatisfactory, the user is allowed to substitute such a value with one from an outside source.

Another option available to the user is the ability to inspect the data in the data base that were used for a particular calculation. For example, the preference classes of each species that were used for determining the amount of unpalatable phytomass in the paddock under consideration can be inspected and/or edited (Fig. 9).

After completion of the calculations to determine the amount of effectively available phytomass, the grazing capacity of the paddock/management unit is calculated (Fig. 10). The domestic animal consumption value that is used in the calculation is set on $1.2 \mathrm{~kg}$ per day, resulting in a potential stocking rate for dry Merino ewes. If the stocking rate for other animal types or classes has to be determined, the daily consumption rate can be edited as required. 


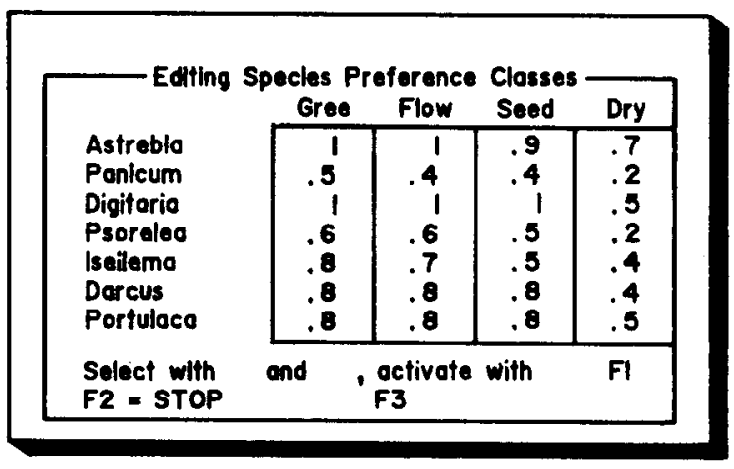

Input progress

0 $100 \%$

Fig. 9. Inspection of preference classes of each species during their different phenological stages, for the purposes of editing.

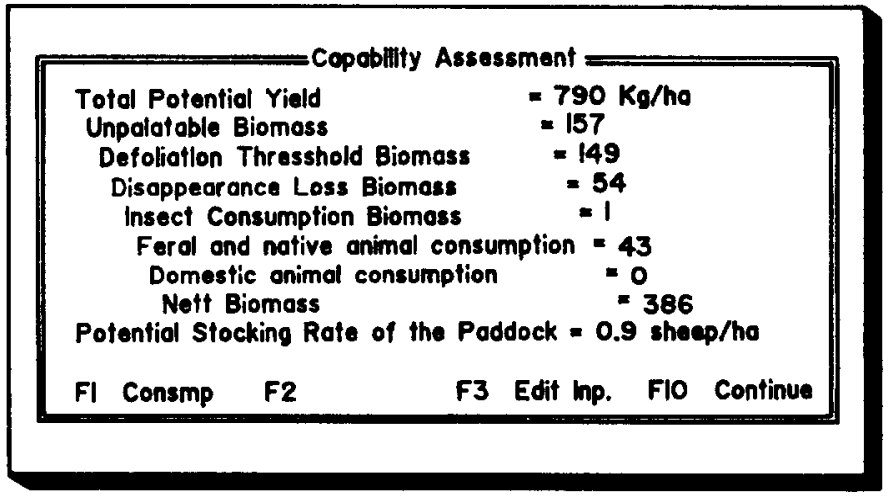

Fig. 10. Result of the potential stocking rate of the paddock under consideration.

(F-keys: see text).

\section{Discussion and Conclusions}

The system that was used to illustrate the integrative approach has specifically been designed for the purposes of condition and grazing capacity assessment of rangelands in which ephemeral populations (seasonal variation) are important. The factors that are used by the expert system to select the appropriate parts of the data base and models for the various calculations are those that determine main floristic differences within a specific biome, vegetation type, or land system. The factors could therefore differ for different areas. For example, in certain areas the rainfall zone or topography might be more important than the season of the year (which was used for designing a system for the Mitchell grasslands), in determining the data base that will be used. Application of the system in another area would therefore require an adjustment of the inference model of the expert system to include those factors that are determining major floristic differences in such an area. New data to populate the data base, as well as restructuring of the data base to accommodate new rules, will be required.

The system further uses a particular condition assessment technique. Although more sophisticated techniques are available (Bosch and Kellner 1991), the weighted average approach that is used in this package has the advantage that it can be applied even in the absence of quantitative data. If data are not available for the quantitative determination of the ecological status of species, it can be qualitatively determined by means of expert knowledge, as the position on the degradation gradient where a particular species would be expected to have its highest abundance.
This advantage also applies to all other input data, which could come from either experimental data, or expert knowledge. Rangeland managers can not wait until a full quantitative understanding of the plant:animal:environment interaction has been developed for all rangelands before a system of this nature is implemented. This approach allows for the implementation of measures based on our existing knowledge.

Continuous quantification of the data inputs and refinement of models in the package should, however, be an integral part of the implementation process. Application of the system is an effective way to reveal the noise in the system, such as unreliable models and nonscientifically based hypotheses/data. By applying and evaluating the system in the field situation, extension officers and rangeland managers could become involved in the refinement process. Their feedback would assist the researchers and knowledge engineers to refine the models or to define new research objectives to improve the input data for the various calculations. This mutual interaction between the researcher and the users is seen as an on-going process to use, evaluate, and improve the system. It will also assist to overcome the gap between theory and practice, in ensuring that research information and guidelines are transferred to extension, and subsequently the land managers, in the most usable form.

The user friendliness of the software is an important factor to ensure its wide acceptance and use. This also conforms to the requirements of rangeland evaluation and monitoring programmes outlined in the recommendations of the International workshop on Land Evaluation in Addis Ababa (Siderius 1984): i.e. that the results, guidelines, etc. be made available in forms understandable to the land user, extension officer and the decision maker. The user friendly expert guidance built into the programme and the use of graphics to enhance human comprehension are important features, increasing the practical value of the package.

The approach to combine various computer technologies into one system seems to be an effective way to provide the industry with useful software. The main advantages of the system can be summarized as follows:

- The interdisciplinary approach of the system ensures that all aspects are considered and not only the main components normally emphasized by specialists in a particular field;

- integrating the various computer technologies optimizes the efficiency of the use of the computer medium, in contrast to using any one of the technologies individually;

- the present state of knowledge can be utilized immediately without elaborated costs before a workable system is available;

- the various stages of qualitative and quantitative data invite easy participation of specialists of various disciplines to contribute their knowledge in the section of the system where their discipline applies, without having to understand the total system;

- the system is developed in such a way that knowledge can easily and inexpensively be accommodated;

- the mouthpiece for decision making, extension and education is unified but based on the opinions of all experts concerned; and

- the system can be applied universally, regardless of the pool of quantitative knowledge that exists.

These advantages are of special importance for the evaluation and monitoring of the many rangeland systems not yet understood and quantified.

\section{Literature Cited}

Barnes, D.I., N.F.G. Rethman, B.H. Beukes, and G.D. Kotze. 1984. Veld composition in relation to grazing capacity. J. Grassl. Soc. Sth. Afr. 1:16-19. 
Bosch, O.J.H. 1989. Degradation of the semi-arid grasslands of southern Africa. J. Arid Environ. 16:143-147.

Bosch, O.J.H., and J. Booysen. 1988. Users manual for the PUK grassland dynamics package. Dept. Plant Sciences, Potchefstroom University for Christian Higher Education. Potchefstroom, South Africa. (Unpublished).

Bosch, O.J.H., and K. Kellner. 1991. The use of a degradation gradient for the ecological interpretation of condition assessments in the western grassland biome of southern Africa. J. Arid Environ. 21:21-29.

Bosch, O.J.H., K. Kellner, and S.H.E Scheepers. 1989a. Degradation models and their use in determining the condition of southern African grasslands. Proc. XVI Int. Grassl. Congr., Oct. 1989. Nice, France.

Bosch, O.J.H., D.M. Orr, J. Scanlan, E. Weston, and J. Carter. 1989 b. Report on the workshop on condition assessment in Mitchell grasslands of western Queensland. Aug. 1989, AZI, Longreach, Australia. (Unpublished).

Christian, K.R., M. Freer, J.R. Donnelly, J.L. Davidson, and J.S. Armstrong. 1978. Simulation of grazing systems. Centre for Agricultural Publishing and Documentation, Wageningen, The Netherlands. p. 115.

Dyksterhuis, E.J. 1949. Condition and management of rangeland based on quantitative ecology. J. Range Manage. 2:104-115.

Foran, B.D., G. Bastin, and K.A. Shaw, 1986. Range assessment and monitoring in arid lands: The use of classification and ordination in range survey. J. Environ. Manage. 22:67-84.

Foran, D.B., N.M. Tainton, and P. deV. Booysen. 1978. The development of a method for assessing the condition of three grassveld types in Natal. Proc. Grassld. Soc. Sth. Afr. 13:27-33.

Haydock, K.P., and N.H. Shaw. 1975. The comparative method for estimating dry matter yield of pasture. Aust. J. Exp. Agr. Anim. Husb. 15:663-670.
McKeon, G.M., K.G. Rickert, and A.J. Ash. 1982. Simulation of production variability from native pastures in south east Queensland: simulation studies. Proc. Aust. Soc. Anim. Prod. 14:208-210.

Mentis, M.T. 1981. Evaluation of the wheel point and step point methods of veld condition assessment. Proc. Grassl. Soc. Sth. Afr. 16:89-94.

Mosley, J.C., S.C. Bunting, and M. Hironaka. 1986. Determining range condition from frequency data in mountain meadows of central Idaho. J. Range Manage. 39:561-565.

Pressland, A.J. 1984. A review of the productivity and management of western Queensland's rangelands. Aust. Range J. 6:28-45.

Schildt, H. 1987. Artificial intelligence using C. Osborne McGraw-Hill, Berkeley, Calif.

Siderius, W. 1984. Recommendations and conclusions. Proc. workshop on land evaluation for extensive grazing, Nov. 1983. Addis Ababa: 3-6.

Tainton, N.M., P.J. Edwards, and M.T. Mentis. 1980. A revised method for assessing veld condition. Proc. Grassl. Soc. Sth. Afr. 15:37-42.

Tueller, P.T., and W.H. Blackburn. 1974. Condition and trend of the big sagebush/needle-and-thread habitat type in Nevada. J. Range Manage. 27:36-40.

Uresk, D.W. 1990. Using multivariate techniques to quantitatively estimate ecological stages in a mixed grass prairie. J. Range Manage. 43:282-285.

Vorster, M. 1982. The development of the ecological index method for assessing veld condition in the Karoo. Proc. Grassl. Soc. Sth. Afr. 19:84-89.

Westoby, M., B.H. Walker, and I. Noy-Meir. 1989. Opportunistic management for rangelands not at equilibrium. J. Range Manage. 42:266-274. 